\title{
Paz na sala de aula é uma condição para o sucesso escolar: que revela a literatura?*
}

Rosilene Beatriz Lopes**

Candido Alberto Gomes****

\section{Resumo}

0 objetivo deste artigo é discutir o tema indisciplina como contribuição visando a uma proposta de educação para a paz, por meio da investigação seletiva da literatura. A contemporaneidade requer a superação do autoritarismo, da opressão e da submissão nas escolas. Para construir processos educacionais autônomos e solidários, dialógicos, emancipatórios e cooperativos, de acordo com Freinet, Freire e outros grandes educadores, este trabalho oferece algumas sugestões para a escola: (i) equipes de intervenção para resolução de problemas, buscando a autogestão escolar, por meio do desenvolvimento de projetos educativos; (ii) currículos significativos, haja vista que concorrem para despertar nos alunos o desejo de aprender, e (iii) o diálogo como meio de pactuar modos de convivência social, com respeito ao amplo leque de diversidades, concebido como riqueza cultural.

Palavras-chave: Disciplina escolar. Violência escolar. Formação de educadores. Gestão escolar.

\section{Peace in the classroom as a condition for} school success: what does the literature reveal?

\section{Abstract}

This paper aims to discuss the issue of indiscipline as a contribution for an educational proposal in favour of peace, based on the selective review of the literature. Contemporary times require overcoming authoritarianism, oppression and submission in schools. Considering the construction of educational processes directed toward the development of autonomy and solidarity, on the basis of dialogue, emancipation and cooperation, according to

* Trabalho integrante do programa de pesquisas da Cátedra UNESCO de Juventude, Educação e Sociedade da Universidade Católica de Brasília.

** Doutoranda em Educação pela Universidade Católica de Brasília; professora das Faculdades Integradas do Norte de Minas (FUNORTE); analista educacional da Superintendência Regional de Ensino de Montes Claros. E-mail: rbeatrizlopes@yahoo.com.br

**** Doutor em Educação (PhD) pela University of California, Los Angeles; professor Titular da Universidade Católica de Brasília. E-mail: clgomes@terra.com.br 
Freinet, Freire and other great educators, this work presents some suggestions for schools: (i) constitution of teams for intervention on the basis of problemsolving, by means of educational project development, aiming school selfmanagement; (ii) planning of significant curricula for stimulating the desire to learn; (iii) the use of dialogue for co-establishing social life rules, based on the respect to diversities as cultural wealth.

Keywords: School discipline. School violence. Teacher education. School management.

\section{Paz en el salón de clase como condición para el suceso escolar: ¿qué revela la literatura? Resumen}

El objetivo del presente trabajo es discutir el tema de la indisciplina en la escuela con vistas a una propuesta educativa a favor de la paz, con fundamento en una revisión selectiva de la literatura. Los tiempos contemporáneos requieren la superación del autoritarismo, opresión y sumisión en las escuelas. Con vistas a la construcción de procesos educativos dirigidos al desarrollo de la autonomía y de la solidaridad, con fundamento en el diálogo, la emancipación y cooperación, según Freinet, Freire y otros grandes educadores, este trabajo propone algunas sugestiones a las escuelas: (i) la constitución de equipos de intervención para la resolución de problemas, mirando a la auto-gestión escolar; (ii) planificación de currículos significativos para estimular el deseo de aprender; (iii) el uso del diálogo para establecer en conjunto normas de la vida social, respectando a las diversidades interhumanas como riqueza cultural.

Palabras clave: Disciplina escolar. Violencia escolar. Formación de educadores. Gestión escolar.

Professores de hoje buscam ansiosamente meios para compreender os processos sociais na sala de aula e as alternativas que o auxiliem a proporcionar um clima de convivência propício ao desenvolvimento da aprendizagem. De fato, num ambiente caótico e ruidoso é mais difícil, se não impossivel, aprender, em particular, aprender a conviver. Por isso mesmo, alunos de licenciatura temem a sala de aula e pedem mais prática, com mais teorias aplicadas aos problemas que enfrentarão (GOMES; PEREIRA, 2009). Que contribuições a vasta literatura oferece não para construir a ordem para ordem, mas para compreender esses processos sociais na sala de aula hoje?

A chamada indisciplina, cada vez mais presente nas preocupações dos professores, não é algo novo. A prática de transgressão e a rebeldia estudantil é tão velha quanto a escola. Na Grécia e Roma antigas a indisciplina acontecia, chicotes e varas usadas contra os discípulos às vezes também eram usadas pelos mesmos contra os mestres (escravos), esses revidavam à mesma altura, espancando ou mesmo matando-os. Também na Idade Média esse tema surgiu nas escolas paroquiais e nos mosteiros, quando 
os jovens driblavam a vigilância dos mestres com diferentes artimanhas. Prova de indisciplina foi o fogo provocado pelos jovens monges do convento de São Galo, em 935, na atual Suiça, com as varas que os mestres os mandaram buscar para fustigálos. Ainda no fim do século XV, o quadro apresentado da educação cortês ou cavalheiresca mostra atos de indisciplina e violência, como o de um cavaleiro que deu um soco no olho do mestre-pedagogo, revidando aos seus castigos (MANACORDA, 1997). A indisciplina surgida se reproduz e permanece no cotidiano das escolas, isoladamente ou convertida em grandes movimentos, como os estudantis, contestatórios, amplos e radicais que ocorreram a partir de maio de 1968, em vários paises (FLEURI, 2008). Esses diferentes contextos mostram que, embora não seja algo novo, os atos considerados como indisciplina possuem diferentes objetivos e alvos e podem contribuir para mudanças de uma "ordem vigente" ou para perpetuar uma cultura de violência.

Atualmente, muitos professores e alunos se queixam das dificuldades do desenvolvimento do processo pedagógico, bem como do mínimo respeito para que se desenvolva uma convivência possível. 0 que se define neste artigo não é a disciplina enquanto docilidade e submissão, mas a abertura ao diálogo, em que a aceitação do outro e das regras não sejam uma imposição, mas o resultado de debate aberto, visando ao respeito às diferenças e à organização do espaço escolar para o desenvolvimento do processo pedagógico, haja vista que até a presente data a escola ainda é considerada um dos grupos sociais de grande contribuição para formar crianças e jovens. Esse debate se faz necessário, haja vista que as escolas comprometidas com propostas democráticas rejeitam o papel tradicional de produtoras de sujeitos disciplinados e ordeiros, entretanto, também não estão assumindo a construção de sujeitos autônomos e autodisciplinados (XAVIER, 2006).

Assim, este artigo busca discutir a construção de processos autônomos e solidáriOS, (FREINET, 1996), dialógicos, emancipatórios e cooperativos (COLOMBIER; MANGEL; PERDRIAULT, 1989; FREIRE, 1997; JARES, 2002;), superando os processos de autoritarismo, dominação e sujeição (FOUCAULT, 1998). 0 lugar destes últimos deve ser ocupado por meio de relações de reciprocidade entre sujeitos educandos/educadores no processo de conhecimento (FLEURI, 2008); numa perspectiva democrática, que venha a estabelecer a convivência possível para o desenvolvimento da prática pedagógica e a dimensão formadora - sistematização, reflexão e apropriação do conhecimento acumulado pela humanidade e produção de novos conhecimentos.

Para desenvolver o tema da convivência entre os diferentes, em relativa paz na sala de aula, este trabalho apresenta alguns conceitos de disciplina/indisciplina, sua abordagem em diferentes correntes pedagógicas, a gestão na sala de aula e propostas de intervenção. Espera-se que os professores e outros profissionais da educação realizem uma autorreflexão a partir das seguintes questões: Qual o seu conceito de disciplina/indisciplina? Que propostas pedagógicas constituem a base da sua prática 
em relação à disciplina/indisciplina na sala de aula? Que intervenções poderá realizar para melhorar o clima de convivência na sala de aula? Espera-se também que os professores sejam construtores de uma educação para a paz na sala de aula. Esse tipo de educação não se concretiza com o uso de técnicas e informações sobre a paz - visão instrucional -, mas derivam das atitudes e, ao nível mais profundo, dos valores internalizados, tais como cooperação e justiça - visão formativa.

\section{Disciplina e Indisciplina: que são, afinal?}

0 termo disciplina, de origem latina e tendo a mesma raiz que discipulo, é marcado pela sua polissemia e vem assumindo ao longo do tempo diferentes significações: punição, instrumento de punição, direção moral, regra de conduta para fazer reinar a ordem numa coletividade; obediência a essa regra (ESTRELA, 2002). "Disciplinas", segundo Foucault (1998), são os métodos que permitem o controle minucioso das operações do corpo, atuando direto sobre o corpo e consequentemente sobre a inteligência e as atitudes. Esses métodos são estratégias de controle social e, para tanto, utilizam-se de vigilância, sanções e exames (FLEURI, 2008). As regras e o tipo de obediência que elas postulam sofrem transformações de acordo com grupos sociais e tempo histórico.

De acordo com o grupo social, os tipos de disciplina se apresentam com diferentes especificidades: familiar, escolar, militar, religiosa, desportiva, partidária, sindical. Embora diferentes, todos têm um ponto comum: inscrevem-se num fundo ético de caráter social, buscando uma harmonia. Assim, a disciplina social é simultaneamente fim imediato e meio da educação (ESTRELA, 2002). Nesse sentido, todo processo educativo utiliza-se da disciplina na escola. Entretanto, deve ser uma disciplina democrática, assentada nos valores do respeito mútuo, indispensável para a convivência, e dos direitos e deveres, fundamentada no diálogo e no equilibrio entre o autoritarismo e a permissividade (JARES, 2002).

A indisciplina, estabelecendo-se como o oposto da disciplina, apresenta-se no contexto escolar numa abordagem plural. Até os anos 70, nas abordagens psicológicas, o conceito estava centrado no aluno, na sua adaptação ou não à escola, nas condutas antissociais e perturbações neuróticas ou de personalidade. A associação com fatores psicológicos, sociais ou pedagógicos desculpabilizavam o aluno. Nesse enfoque foram objetos de estudo o insucesso escolar, a autoridade no lar, a etnia, a idade, o gênero e as atitudes e opiniões dos professores e alunos. Buscava-se caracterizar o fenômeno segundo esses fatores, bem como descobrir suas causas para uma intervenção eficaz (CAEIRO; DELGADO, 2005).

Nas últimas décadas o conceito se amplia, a indisciplina passa a ser vista como um fenômeno multicausal. Portanto, para compreendê-la é necessário considerar vários fatores, como: a vida escolar do aluno, a escola, a turma e o professor, o currículo e a metodologia, a família e a sociedade (CAEIRO; DELGADO, 2005; CARITA; FERNANDES, 2002), a organização física e administrativa da escola (BARBOSA; XAVIER, 2006), além do próprio 
conceito de disciplina/indisciplina vigente. Dentre os fatores pedagógicos destaca-se a relação professor-aluno, o desencontro entre regras e expectativas e a organização criada pelo professor na sala de aula, bem como percepções e pontos de vista diferentes sobre situações ocorridas que podem gerar situações potenciais de conflito. Assim, a indisciplina passa a ser construída na própria sala de aula, como resultado desse processo de interação (CAEIRO; DELGADO, 2005), constituindo-se em 'termômetro' da relação professor-aluno e do trabalho do professor, seu papel e função (AQUINO, 1998b).

Esse processo de interação se torna cada vez mais complexo, haja vista que o perfil da escola atual é o da diversidade, os alunos são diferentes nas origens sociais, na renda familiar, na etnia, na expectativa do futuro, nos valores éticos e outros (BOGGINO, 2005; CHRISPINO; CHRISPINO, 2011). Nesse contexto, a indisciplina pode surgir quando se estabelecem falhas na comunicação, os 'diferentes' não compreendem os códigos verbais, paraverbais e não-verbais utilizados no ambiente escolar, como exemplo, certos gestos do aluno, interpretados pelo professor como ofensivos, têm significados diferentes em seu meio social. A escola não leva em consideração hábitos e discursos próprios dos alunos. Isso pode torná-los desmotivados, passando a rejeitar a escola. (CAEIRO; DELGADO, 2005; ESTRELA, 2002).

A indisciplina, considerada um fenômeno polissêmico e multicausal, também se apresenta em diferentes níveis. Para [Amado (20-?)] existem três níveis de indisciplina: (i) o desvio das regras de produção da aula; (ii) conflitos entre os pares que se exprimem por agressões verbais e físicas e danos materiais; (iii) agressões a professores, desde insultos até agressões físicas, de comportamentos de contestação até reequilibrio do prestígio junto aos colegas. Esses níveis estão relacionados à faixa etária e ano de escolaridade: nos anos iniciais do ensino fundamental são considerados os comportamentos que vão contra as regras relativas a espaço e comunicação; nos anos finais, os comportamentos que se opõem ao professor e, no ensino médio, a indisciplina se dirige, sobretudo, ao professor (ESTRELA, 2002).

\section{Disciplina/Indisciplina: concepções pedagógicas}

Ao longo do tempo, a disciplina/indisciplina foi concebida de diferentes perspectivas pelas concepções pedagógicas. Cada corrente buscava estabelecer coerência entre seus pressupostos e objetivos e, quando bem executada, atendia aos mesmos. 0 problema a ser questionado na atualidade é: os pressupostos e objetivos de alguma(s) pedagogia(s) ainda são adequados e suficientes para a formação do aluno hoje, vivendo em regime democrático e num mundo complexo e instável?

A resposta é negativa e pode ser revelada pelas tentativas fracassadas de escolas e professores que não conseguem manter os alunos em ordem, ou em modelo "figurino". Muitos professores ainda buscam preservar o lugar central na organização do ato pedagógico (ESTRELA, 2002), tentando impor uma relação de respeito fundada nas noções de hierarquia e superioridade (AQUINO, 1998b). 
Portanto, torna-se importante entender o caminho percorrido pelas diversas correntes pedagógicas e suas tentativas de lidar com a indisciplina de diferentes formas, para entender a atualidade e buscar intervir, considerando a escola e 0 aluno que temos no momento histórico atual. Para tanto, os Quadros 2, 3 e 4 apresentam uma síntese não exaustiva dessas pedagogias, dos conceitos de disciplina/indisciplina e de intervenções e práticas pedagógicas utilizadas.

0 quadro 2 mostra a mudança de paradigmas entre a concepção tradicional e da educação nova. No Brasil, Saviani (2008) apresenta a divisão desta tendência tradicional em dois períodos: (i) entre 1549 e 1759, do monopólio da vertente religiosa da pedagogia tradicional, e (ii) entre 1759 e 1932, das ideias pedagógicas no Brasil, coexistindo as vertentes religiosa e leiga da pedagogia tradicional. Entretanto, essa tendência permaneceu por muito mais tempo, como pode ser verificado no estudo de caso realizado por Pereira (1967). 0 autor constatou que, em 1958/ 1959, numa escola metropolitana de postura tradicional, o conceito de disciplina ainda estava relacionado com "submissão" e as medidas de intervenção propostas eram "reprovativas, como castigos corporais".

Quadro 2- Disciplina X indisciplina na pedagogia tradicional e na educação nova.

\begin{tabular}{|c|c|c|c|c|}
\hline $\begin{array}{l}\text { Pedagogia } \\
\text { (início) }\end{array}$ & Defensores & $\begin{array}{c}\text { Conceito de } \\
\text { Disciplina/Indisciplina }\end{array}$ & Intervenções & $\begin{array}{c}\text { Práticas } \\
\text { Pedagógicas }\end{array}$ \\
\hline $\begin{array}{c}\text { Tradicional } \\
\text { (Idade Antiga) }\end{array}$ & & $\begin{array}{l}\text { Aluno calado, quieto, } \\
\text { atento, obediente e } \\
\text { respeitador. } \\
\text { Submissão das } \\
\text { crianças aos } \\
\text { professores e } \\
\text { diretores: acatamento } \\
\text { total de suas decisões, } \\
\text { tratamento } \\
\text { reverencial e mesmo } \\
\text { temeroso. }\end{array}$ & $\begin{array}{l}\text { Notas baixas de } \\
\text { "comportamento } \\
\text { ", expressões } \\
\text { injuriosas e } \\
\text { castigos } \\
\text { corporais. }\end{array}$ & $\begin{array}{c}\text { Magistrocentri- } \\
\text { cismo, ou seja, } \\
\text { centralização no } \\
\text { professor e na sua } \\
\text { palavra, o que } \\
\text { exige ordem para } \\
\text { que a mensagem } \\
\text { não seja } \\
\text { perturbada por } \\
\text { ruídos indesejáveis. }\end{array}$ \\
\hline $\begin{array}{c}\text { Educação } \\
\text { Nova } \\
\text { (1921) }\end{array}$ & $\begin{array}{c}\text { Dewey } \\
(1859-1992)\end{array}$ & $\begin{array}{l}\text { Disciplina baseada no } \\
\text { exercício da liberdade } \\
\text { e da responsabilidade, } \\
\text { dispensando a } \\
\text { coerção externa. } \\
\text { Autocontrole. } \\
\text { Autogoverno. }\end{array}$ & $\begin{array}{c}\text { Não exclui as } \\
\text { sanções, mas as } \\
\text { crianças } \\
\text { submetem-se a } \\
\text { elas mais } \\
\text { facilmente } \\
\text { porque } \\
\text { contribuíram } \\
\text { para elaborar as } \\
\text { regras. }\end{array}$ & $\begin{array}{c}\text { Pedagogia ativa } \\
\text { baseada nos } \\
\text { interesses do } \\
\text { aluno, respeitando } \\
\text { as teorias do } \\
\text { desenvolvimento } \\
\text { infantil. }\end{array}$ \\
\hline
\end{tabular}


(continuação)

\begin{tabular}{|c|c|c|c|c|}
\hline $\begin{array}{c}\text { Educação } \\
\text { Nova } \\
(1921)\end{array}$ & $\begin{array}{c}\text { Maria } \\
\text { Montessori } \\
(1870-1952)\end{array}$ & $\begin{array}{l}\text { Disciplina não é um } \\
\text { fim, mas um caminho. } \\
\text { Noção diferente de } \\
\text { ordem, o que não } \\
\text { significa anarquia ou } \\
\text { desordem. }\end{array}$ & $\begin{array}{l}\text { A disciplina não } \\
\text { poderá ser } \\
\text { obtida por meio } \\
\text { de sermões e } \\
\text { ordens. }\end{array}$ & $\begin{array}{l}\text { Centrada na } \\
\text { participação do } \\
\text { aluno como } \\
\text { incentivo à } \\
\text { autonomia. } \\
\text { Ambiente } \\
\text { interativo, os } \\
\text { alunos podem } \\
\text { manipular os } \\
\text { materiais } \\
\text { pedagógicos. }\end{array}$ \\
\hline $\begin{array}{l}\text { Educação } \\
\text { Libertadora } \\
\text { Pedagogia do } \\
\text { Oprimido } \\
\text { (1962) }\end{array}$ & $\begin{array}{c}\text { Freire } \\
(1921-1997)\end{array}$ & $\begin{array}{c}\text { Disciplina implica em } \\
\text { uma relação entre o } \\
\text { professor e o aluno, } \\
\text { em que a autoridade } \\
\text { está situada na } \\
\text { liberdade as(dia de } \\
\text { ambos. }\end{array}$ & Diálogo & $\begin{array}{c}\text { Educação } \\
\text { problematizadora: } \\
\text { estabelece o } \\
\text { diálogo como } \\
\text { forma de } \\
\text { comunicação } \\
\text { pedagógica. } \\
\text { Educador e } \\
\text { educando como } \\
\text { sujeitos do } \\
\text { processo. }\end{array}$ \\
\hline
\end{tabular}

Fonte: Dewey (1959), Freire (1985)e Estrela (2002).

Surgindo no início do século XX, a educação como exercício de liberdade e responsabilidade recebeu influência das correntes psicanaliticas, que criticavam a escola tradicional, apresentando-a como repressiva, ao pretender ignorar e recalcar a irracionalidade das pulsões e do desejo (ESTRELA, 2002). 0 foco muda, passando da heteronomia para a conquista da autonomia e da autodisciplina como fim prioritário da educação. Autocontrole e autogoverno são princípios da Educação Nova (Quadro 2), iniciada por Dewey (1959). Maria Montessori também revoluciona a postura tradicional, quando transforma a sala de aula em ambiente estimulador, por meio de materiais pedagógicos que a criança pode manipular. 0 predomínio dessa pedagogia no Brasil, segundo Saviani (2008), corresponde ao terceiro período, entre 1932 e 1969, revelando-se, no movimento de educação popular, com a liderança maior de Paulo Freire, defensor da prática da liberdade, do diálogo professor-aluno e da autonomia do educando (FREIRE, 1997).

Nessa linha de pensamento a vida coletiva precisava de disciplina, que devia manifestar-se sob vários aspectos, tais como a higiene do corpo e o cumprimento de regras (ESTRELA, 2002).

0 conceito de disciplina também se faz presente no pensamento educativo socialista (Quadro 3), sendo apresentado na obra de Makarenko e na pedagogia de Freinet. 
A pedagogia de Freinet (1960) associa o trabalho produtivo e a descoberta da realidade no cotidiano da escola. 0 autor iniciou os movimentos na pedagogia ocidental que marcaram a conquista de autonomia individual por meio da participação responsável na vida coletiva. 0 trabalho com o conselho cooperativo e a utilização de técnicas, como a imprensa, o texto livre e outras, mostraram uma nova organização social da aula.

Quadro 3 - Disciplina /indisciplina na educação socialista.

\begin{tabular}{|c|c|c|c|c|}
\hline $\begin{array}{l}\text { Peda- } \\
\text { gogia } \\
\text { (início) }\end{array}$ & Defensores & $\begin{array}{l}\text { Conceito de } \\
\text { Disciplina/ } \\
\text { Indisciplina }\end{array}$ & Intervenções & $\begin{array}{l}\text { Práticas } \\
\text { Pedagógicas }\end{array}$ \\
\hline \multirow[b]{2}{*}{$\begin{array}{l}\text { Edu- } \\
\text { cação } \\
\text { Sócia- } \\
\text { lista } \\
\text { (1917) }\end{array}$} & $\begin{array}{l}\text { Makarenko } \\
(1888-1939)\end{array}$ & $\begin{array}{c}\text { A disciplina } \\
\text { insere-se no } \\
\text { quadro da ação } \\
\text { social coletiva e } \\
\text { é sua resultante } \\
\text { natural. }\end{array}$ & $\begin{array}{c}\text { As regras, } \\
\text { prêmios e } \\
\text { punições são } \\
\text { estabelecidos } \\
\text { pela assembleia } \\
\text { geral, principal } \\
\text { órgão de gestão. }\end{array}$ & $\begin{array}{c}\text { Organiza-se em } \\
\text { grupos de estudo, } \\
\text { de modo a } \\
\text { favorecer o } \\
\text { sentimento de } \\
\text { pertencimento à } \\
\text { coletividade e } \\
\text { subordinação dos } \\
\text { interesses } \\
\text { individuais aos } \\
\text { coletivos. }\end{array}$ \\
\hline & $\begin{array}{l}\text { Freinet } \\
(1896-1966)\end{array}$ & $\begin{array}{c}\text { A disciplina é } \\
\text { concebida como } \\
\text { organização, } \\
\text { planificação e } \\
\text { também } \\
\text { dinamismo e } \\
\text { vida. } \\
\text { A indisciplina } \\
\text { consiste num } \\
\text { ato de rebelião } \\
\text { contra a regra } \\
\text { de vida coletiva } \\
\text { e contra o } \\
\text { grupo, sua } \\
\text { manutenção é } \\
\text { uma tarefa } \\
\text { coletiva. Ela é } \\
\text { provocada pelas } \\
\text { falhas das } \\
\text { estratégias } \\
\text { pedagógicas. }\end{array}$ & $\begin{array}{l}\text { A disciplina não } \\
\text { se impõe com } \\
\text { sanções, é } \\
\text { consequência da } \\
\text { organização do } \\
\text { trabalho pelo } \\
\text { professor. } \\
\text { Conflitos são } \\
\text { regulados pelo } \\
\text { grupo por meio } \\
\text { de conselho } \\
\text { cooperativo. } \\
\text { A regra é: cada } \\
\text { um pode criticar } \\
\text { e ser criticado, } \\
\text { incluindo o } \\
\text { professor. }\end{array}$ & $\begin{array}{c}\text { Classe cooperativa, } \\
\text { conselho } \\
\text { cooperativo da } \\
\text { turma - os alunos } \\
\text { refletem de modo } \\
\text { concreto sobre os } \\
\text { problemas de } \\
\text { natureza legislativa } \\
\text { e executiva ligados } \\
\text { a qualquer tipo de } \\
\text { trabalho. } \\
\text { As atividades são } \\
\text { organizadas } \\
\text { escutando os } \\
\text { desejos dos alunos. } \\
\text { Educador e } \\
\text { educando: relação } \\
\text { de diálogo, numa } \\
\text { postura liberal. }\end{array}$ \\
\hline
\end{tabular}

Fonte: Freinet (1960) e Estrela (2002). 
As correntes pedagógicas da década de 1960 (Quadro 4) apresentaram pensamentos divergentes, começando pelas pedagogias não diretivas, que radicalizaram posições e colocaram em causa a própria noção de disciplina e o papel do professor na retomada do conceito junto à discussão sobre valores.

A corrente de clarificação de valores trouxe uma importante contribuição para a compreensão dos problemas disciplinares. Afirma que a origem das situações conflituais se assenta na falta ou na indefinição de valores e defende que a função da escola consiste também em ajudar os alunos a escolherem os seus valores e a agirem segundo eles. Diferentes procedimentos didáticos são empregados para facilitar o autoconhecimento e a auto-orientação do aluno, tais como: planos de trabalho; contratos; questionários sobre os objetivos, sentimentos e valores; debates; conselhos; mediação dos conflitos; entre outros, também são propostos por diversos autores (CARITA; FERNANDES, 2002; ESTRELA, 2002; JARES, 2002; COLOMBIER; MANGEL; PERDRIAULT, 1989).

Quadro 4 - Disciplina X indisciplina nas correntes pedagógicas da década de 1960.

\begin{tabular}{|c|c|c|c|c|}
\hline $\begin{array}{l}\text { Pedagogia } \\
\text { (início) }\end{array}$ & Defensores & $\begin{array}{l}\text { Conceito de } \\
\text { Disciplina } \\
\text { Indisciplina }\end{array}$ & Intervenções & Prática Pedagógica \\
\hline $\begin{array}{l}\text { Pedagogia } \\
\text { institu- } \\
\text { cional } \\
\text { (Década de } \\
\text { 1960) }\end{array}$ & $\begin{array}{c}\text { Lobrot } \\
(1924-. . .) \\
\text { Lapassade } \\
(1924- \\
2008) \\
\text { Lourau } \\
(1933- \\
2000)\end{array}$ & $\begin{array}{l}\text { Disciplina é } \\
\text { relacionada com a } \\
\text { autogestão. } \\
\text { Criar instituições } \\
\text { internas } \\
\text { satisfatórias é o } \\
\text { processo educativo } \\
\text { por excelência. }\end{array}$ & $\begin{array}{l}\text { Não intervenção } \\
\text { do professor, } \\
\text { mesmo se } \\
\text { solicitado, pois } \\
\text { há pedidos a } \\
\text { que o professor } \\
\text { não deve } \\
\text { satisfazer. }\end{array}$ & $\begin{array}{l}\text { Professor e alunos } \\
\text { são cúmplices, na } \\
\text { medida em que há o } \\
\text { objetivo comum de } \\
\text { contestar a } \\
\text { burocracia da escola } \\
\text { e a própria } \\
\text { sociedade. Defende a } \\
\text { autogestão como } \\
\text { instrumento que } \\
\text { permite a dialética } \\
\text { do "instituindo" e do } \\
\text { "instituido". }\end{array}$ \\
\hline $\begin{array}{c}\text { Pedagogia } \\
\text { não } \\
\text { diretiva } \\
\text { (1960) }\end{array}$ & $\begin{array}{c}\text { Carl Rogers } \\
\text { (1902- } \\
1987)\end{array}$ & $\begin{array}{l}\text { Indisciplina como } \\
\text { fenômeno } \\
\text { transitório e } \\
\text { necessário, haja } \\
\text { vista que a } \\
\text { desordem precede } \\
\text { a necessidade } \\
\text { sentida da ordem. }\end{array}$ & $\begin{array}{l}\text { Critica as } \\
\text { censuras ou } \\
\text { punições } \\
\text { advindas do } \\
\text { professor e } \\
\text { defende a } \\
\text { decisão do } \\
\text { grupo quanto às } \\
\text { medidas a } \\
\text { serem tomadas } \\
\text { em relação aos } \\
\text { que prejudicam } \\
\text { o seu } \\
\text { funcionamento. }\end{array}$ & $\begin{array}{l}\text { Função do professor: } \\
\text { facilitador. Ele é um } \\
\text { recurso à disposição } \\
\text { do grupo. } \\
\text { Atitudes em relação } \\
\text { aos alunos: } \\
\text { "autenticidade", } \\
\text { "consideração } \\
\text { incondicional } \\
\text { positiva" e } \\
\text { "compreensão } \\
\text { empática". }\end{array}$ \\
\hline
\end{tabular}


(continuação)

\begin{tabular}{|c|c|c|c|c|}
\hline $\begin{array}{c}\text { Pedagogia } \\
\text { não } \\
\text { diretiva } \\
(1960)\end{array}$ & $\begin{array}{c}\text { Carl Rogers } \\
\text { (1902- } \\
1987)\end{array}$ & $\begin{array}{l}\text { Indisciplina como } \\
\text { fenômeno } \\
\text { transitório e } \\
\text { necessário, haja } \\
\text { vista que a } \\
\text { desordem precede } \\
\text { a necessidade } \\
\text { sentida da ordem. }\end{array}$ & $\begin{array}{l}\text { Critica as } \\
\text { censuras ou } \\
\text { punições } \\
\text { advindas do } \\
\text { professor e } \\
\text { defende a } \\
\text { decisão do } \\
\text { grupo quanto às } \\
\text { medidas a } \\
\text { serem tomadas } \\
\text { em relação aos } \\
\text { que prejudicam } \\
\text { o seu } \\
\text { funcionamento. }\end{array}$ & $\begin{array}{l}\text { Função do professor: } \\
\text { facilitador. Ele é um } \\
\text { recurso à disposição } \\
\text { do grupo. } \\
\text { Atitudes em relação } \\
\text { aos alunos: } \\
\text { "autenticidade", } \\
\text { "consideração } \\
\text { incondicional } \\
\text { positiva" e } \\
\text { "compreensão } \\
\text { empática". }\end{array}$ \\
\hline
\end{tabular}

Fonte: Raths (1977), Lobrot (1977), Rogers (1978), Passade (1989), Estrela (2002) e Boggino (2005).

$\mathrm{Na}$ corrente de clarificação de valores cabe ao professor promover a vivência dos valores que estão na base da autodisciplina e da convivência democrática (BOGGINO, 2005; ESTRELA, 2002). Uma das dificuldades apresentadas para a efetivação desse trabalho seriam as contradições do nosso tempo: Relativizar os valores e a liberdade individual da sua escolha ou lutar por direitos que são considerados universais? A proposta de Demo (2005), éticas multiculturais, pode contribuir para a superação deste paradoxo. Para o autor, todas as culturas são incompletas, devem ser reconhecidas como complementares e não como rivais. Isso contribuirá para o enriquecimento mútuo, a convivência em relativa harmonia e conflito, prevalecendo o bem comum.

Essas diferentes concepções pedagógicas mostraram a transição de conceitos no decorrer do tempo, de uma disciplina imposta para a autodisciplina, da heteronomia para a autonomia e desta para a participação nos grupos sociais da escola. 0 percurso a ser realizado pelo aluno poderá ser estimulado ou dificultado, dependendo em grande parte da prática cotidiana do professor em sala de aula. Por isso, se faz necessário reconhecer a importância deste profissional e oferecer subsídios para que o mesmo faça uma reflexão contínua sobre as propostas nas quais atua, se está entendendo e atendendo aos princípios do desenvolvimento psicológico e social da criança e do adolescente, proporcionando-lhes os meios para isso e incentivando uma tomada progressiva de responsabilidade.

\section{Professor: decisor em sala de aula}

A sala de aula é o cemitério comum de numerosas reformas educacionais. Estas se frustram quando não chegam à prática. Opaca para muitos dirigentes, atrás das portas de suas salas de aulas, os mestres guardam uma tradição de autonomia e 
uma gramática própria (GOMES, 2005). Por isso, nada se muda sem conquistar o docente, que é o decisor estratégico, encarregado de traduzir teorias e planos em atos. Ele é o profissional responsável por organizar o tempo e o espaço da sala de aula, por manter um clima favorável para a aprendizagem e a proteção dos alunos sob a sua responsabilidade. Entretanto, segundo Caeiro e Delgado (2005), nem todos conseguem cumprir este papel, que a cada dia se torna mais complexo. Alunos e docentes precisam aprender a conviver, um dos pilares da educação no século XXI (DELORS et al., 2001). Diante desse contexto indaga-se: como os professores organizam a sala de aula? Como isso contribui para a disciplina/indisciplina?

Kounin (1970) considera a existência de dois tipos de professores: bons e maus organizadores da sala de aula. Os primeiros apresentam de modo claro as suas expectativas quanto ao comportamento dos alunos. Os segundos empregam regras vagas e procedimentos desajustados, com diretivas pouco precisas, e comunicam de modo ambíguo as suas expectativas. Essas posturas se refletem no comportamento do aluno, que pode se apresentar disciplinado com os primeiros e indisciplinado com os segundos. Sua indisciplina desponta de acordo com as circunstâncias, indício de que a intervenção docente não está se estabelecendo e seus resultados não estão de acordo com o esperado (AQUINO, 1998b).

Além de diferenças de comportamento em uma mesma sala com diferentes professores, também podem coexistir em uma mesma escola diferentes tipos de turmas, aquelas consideradas disciplinadas e indisciplinadas. Por que isso acontece quando os alunos pertencem a um mesmo grupo social e têm níveis de aprendizagem semelhantes? Uma das questões destacadas é o trabalho do professor. A partir dos tipos de sala de aula descritos por Good e Brophy (1984), confrontados com as características dos professores discutidas por Fleuri (2008) e Caeiro; Delgado (2005), o Quadro 5 foi organizado para visualizar como esses elementos podem estar intrinsecamente relacionados. A sala regida (1) pela anomia - falta de referência a regras práticas de vida em sociedade (DURKHEIM, 2002), (2) pela heteronomia - o cumprimento da regra é imperioso e interpretações diferentes não correspondem a atitudes corretas, e (3) autonomia - as regras são legitimadas por meio de acordos mútuos (PIAGET, 1977).

0 quadro sugere que é preciso desenvolver competências necessárias para a gestão da sala de aula, como envolver os alunos em suas aprendizagens e em seu trabalho (PERRENOUD, 2000), para que seja assegurado um clima propício ao desenvolvimento da aprendizagem. Para tanto, duas dimensões precisam ser objeto de reflexão e de prática: a dimensão de envolvimento com o trabalho - na organização e execução das atividades didáticas e com as pessoas - no relacionamento interpessoal da turma (CARITA; FERNANDES, 2002), tratando o aluno como pessoa (MACHADO, 2000). Indisciplina e falhas de aprendizagem costumam andar de mãos dadas, o que requer do professor a primeira dimensão. A falta de competências básicas na área da leitura 
e escrita pelos alunos, associada a metodologias inadequadas, pode gerar a perturbação nas aulas. Para que haja aprendizagem é necessário que o professor trabalhe numa proposta inclusiva, "individualizando o processo" (PERRENOUD, 2000).

Quadro 5 - Disciplina e indisciplina: tipos de sala de aula e caracteristicas dos professores.

\begin{tabular}{|c|c|}
\hline Tipos de salas de aula & Caracteristicas dos professores \\
\hline $\begin{array}{l}\text { Caos contínuo e ruidos } \\
\text { Anomia, direcionamento exaustivo por } \\
\text { parte da escola para manter um bom } \\
\text { clima. }\end{array}$ & $\begin{array}{l}\text { Laissez-faire } \\
\text { Permissividade (descontrole da aula, ineficácia } \\
\text { das aprendizagens) } \\
\text { Indiferença (rotina, monotonia) }\end{array}$ \\
\hline $\begin{array}{l}\text { Não tem problemas disciplinares, o } \\
\text { controle é apertado e rígido. } \\
\text { Heteronomia, o clima parece tranquilo, } \\
\text { porém, na ausência do professor, a } \\
\text { turma perde o controle. }\end{array}$ & $\begin{array}{l}\text { Professores rigorosos - os alunos atuam com } \\
\text { mais cautela. } \\
\text { Autoritarismo (rigidez, agressividade, } \\
\text { prepotência) }\end{array}$ \\
\hline $\begin{array}{l}\text { Governar-se por si própria. } \\
\text { Autonomia, a turma consegue um bom } \\
\text { clima com ou sem a presença do } \\
\text { professor. }\end{array}$ & $\begin{array}{l}\text { Professores educadores - aqueles que estimulam } \\
\text { o grupo a conhecer os seus caminhos e objetivos } \\
\text { e dirigir-se para alcançá-los, têm a direção do } \\
\text { grupo, isto é, têm claro os objetivos } \\
\text { estabelecidos pela turma. }\end{array}$ \\
\hline
\end{tabular}

Fonte: Good e Brophy (1984), Durkheim (2002), Caeiro, Delgado (2005), Fleuri (2008) e Piaget (1977).

A dimensão com as pessoas requer dos professores a utilização de ações preventivas, muito mais que as de controle e repressivas. São ações que desenvolvem a autonomia, construídas por meio de cooperação e não de coerção. Isso exige transparência das regras do jogo, ter confiança no sucesso do aluno, inspirar confiança, responder calmamente, firmemente, friamente e alegremente quando a turma tenta colocá-los à prova (BOGGINO, 2005; CARITA; FERNANDES, 2002; FELOUZIS, 2000). Alguns comportamentos que precisam ser abandonados: rotular o aluno como indisciplinado e mal educado, relacionando esse comportamento com o da familia. Isso se generaliza entre os docentes e contribui para alicerçar ainda mais essa mesma característica na mente do aluno (CAEIRO; DELGADO, 2005) "negociar" abertamente o silêncio por uma atividade considerada prazerosa, como, por exemplo, um passeio fora da escola. Isso estabelece uma relação falsa de troca que se repetirá entre os alunos para obter o prêmio novamente, elogiar uma turma como a mais comportada, pois gera rivalidade entre ela e outras (TULESKI et a.I, 2005).

Para uma boa gestão da sala de aula, Kounin (1970) sugere algumas técnicas de organização, apresentadas após trabalho de observação em vídeo: capacidade de mostrar para a turma que o professor sabe o que está acontecendo, ainda que 
esteja de costas; atenção simultânea a mais de uma situação; ritmo, sequência de ações, com início e fechamento; suavidade na transição das tarefas; apresentação de uma variedade de estímulos e capacidade de manter o grupo ocupado na realização de atividades comuns.

Para obter um ambiente propício à aprendizagem por meio da mediação para resolver os problemas que surgem na sala de aula, o Quadro 6, organizado a partir da fundamentação de Caeiro e Delgado (2005) e da investigação desenvolvida por Kounin (1970), oferece sugestões aos professores. 0 primeiro passo seria detectar os comportamentos que não condizem com as regras estabelecidas com precisão pelo grupo (CAEIRO; DELGADO, 2005; KOUNIN, 1970) ou os conflitos surgidos (JARES, 2002) e intervir rapidamente.

Quadro 6 - Gestão de turma.

\section{Sugestão: Gestão conveniente dos problemas}

- "Olho de lince", detectar o comportamento indisciplinado ou o conflito surgido imediatamente.

- Sobreposição, detectar o(s) aluno(s) que agiu (agiram) de modo inadequado ou a situação de conflito gerada e lidar com a situação sem desestruturar as atividades propostas.

- Investigação sobre a influência do contexto no comportamento.

- Rapidez para agir diante da situação, capacidade para conduzir um incidente grave.

- Encaminhamento do(s) envolvido(s) aos mediadores para a resolução do conflito, para evitar que o mesmo não se torne crônico e venha a constituir um elemento desestabilizador do grupo.

Fonte: Caeiro e Delgado (2005) e Kounin (1970).

\section{Pela Construção de Processos Autônomos, Dialógicos, Emancipatórios e Cooperativos}

\section{Equipes de intervenção para resolução de problemas}

Os modelos de "resolução de problemas" de Short e colaboradores (ESTRELA, 2002) e de "mediação" (JARES, 2002) apresentam um trabalho de intervenção com equipes permanentes da comunidade escolar, capacitadas em mediação para resolução de problemas.

A relevância da formação dessas equipes é traduzida nos objetivos a serem alcançados, tais como: ajudar os professores na resolução de problemas de disciplina; identificar e prevenir problemas; intervir junto aos estudantes com histórico de dificuldades disciplinares na escola; orientar estudantes com obstáculos de aprendizagem e comportamento e outros. Elas constituem um mecanismo não impositivo de tomada de decisões, reduzem custos e contribuem para melhorar os problemas surgidos em sala de aula (ESTRELA, 2002). 
A criação desses espaços deliberativos e conselhos nas escolas também é defendida por vários autores (FLEURI, 2008; FREINET, 1960; JARES, 2002; PERRENOUD, 2000). Entretanto, a participação não pode ser reduzida a uma instância formal, hierárquica e burocrática, mas requer espaço de participação da comunidade, propiciando a dinâmica da auto-gestão escolar, por meio do desenvolvimento de projetos educativos (FLEURI, 2008; GADOTI, 1998; MACHADO, 2000; PEREIRA, 2008; VEIGA, 1998).

Quadro 7 - Mediação de situações de indisciplina.

\section{Sugestão: Equipes de Mediação para Resolução de Problemas}

1. Constituição da equipe por turno: um professor, um membro da gestão da escola, um técnico de apoio (pedagogo, psicopedagogo, professor com experiência em educação inclusiva) e um pai de aluno.

2. Capacitação sobre os temas: conflito, indisciplina, violências nas escolas e outros afins.

3. Levantamento de alunos que a escola considera como casos de indisciplina.

4. Análise da vida escolar e familiar, relacionamento com os professores, percepção dos professores sobre o aluno e aprendizagem.

5. Organização de portfólio.

6. Levantamento e avaliação das intervenções realizadas e proposta de nova intervenção.

7. Mediação e acompanhamento sistemático.

Fonte: Estrela (2002), Freinet (1960), Fleuri (2008), Jares (2002), e Perrenoud (2000).

\section{Currículo significativo}

0 currículo constitui um processo que intervém no contexto da sala de aula e pode colaborar para a indisciplina, haja vista que é limitado em face da diversidade e dos interesses dos alunos (CARITA; FERNANDES, 2002; JARES, 2002). Diante dessa constatação, professores e coordenadores pedagógicos/supervisores são chamados à responsabilidade de enriquecê-lo com os temas atuais, locais e de acordo com a aprendizagem da turma e de cada aluno, planejando e executando atividades viáveis e atrativas. Dentre os procedimentos, destaca-se o ensino individualizado porque diminui os comportamentos antissociais na sala de aula e aumenta o sucesso na aprendizagem (BEANE, 2006; PERRENOUD, 2000), como sugere o Quadro 8. Práticas pedagógicas dinâmicas são eficazes para controlar a indisciplina, aulas monótonas ou mal preparadas se tornam uma fonte de instabilidade e desordem entre os alunos (CAEIRO; DELGADO, 2005; GOMES; LOPES, 2005; OLIVEIRA; LOPES, 2006).

Quadro 8 - Retomando os resultados das avaliações.

\section{Sugestão: Individualizar estratégias pedagógicas}

Entregar individualmente para o aluno os trabalhos e avaliações.

Entregar individualmente para a família os resultados bimestrais ou trimestrais.

Individualizar estratégias a partir do resultado com o aluno, trabalhando a partir dos erros e dos obstáculos a aprendizagem.

Fonte: Sugestão organizada a partir de proposta de Perrenoud (2000). 
Portanto, o professor não deve se submeter à imposição de um programa formal, que desconsidera o contexto dos alunos, ignora os problemas vividos e o diagnóstico de aprendizagem. Compete a ele, junto à coordenação pedagógica, adequálo à realidade e contextualizar os conteúdos, valorizando a cultura local. Nesta perspectiva, o currículo e a programação didática terão uma função ecológica, uma tarefa articulada de informações entre educandos e educadores (FLEURI, 2008).

\section{Abertura ao diálogo}

A disciplina ou indisciplina se estabelece na comunicação pedagógica, que se regula por regras explícitas e implícitas, impostas ou negociadas pelo professor. 0 clima propício ao desenvolvimento das atividades pedagógicas em aula surge com a distribuição equitativa da comunicação por todos os alunos. Entretanto, isso nem sempre acontece. Basta uma observação das interações verbais e não verbais em sala de aula para verificar que a comunicação é distribuida irregularmente. Desta forma, o professor cria "desertos de comunicação" e monopoliza a comunicação em suas aulas, sempre se relacionando com os mesmos alunos, enquanto os outros se sentem ignorados (ESTRELA, 2002). Assim, como a conversa e os comportamentos dos alunos são sentidos pelo professor como uma violência, o mesmo sentimento é gerado em alguns alunos pela interdição à sua palavra e ao seu movimento (COLOMBIER; MANGEL; PERDRIAULT, 1989; DEBARBIEUX; BLAYA, 2002). Esses aspectos podem ser identificados e minimizados ou superados, como sugere o quadro a seguir.

Quadro 9 - Distribuindo a comunicação.

\section{Sugestão: Registro e análise das comunicações verbais}

$1^{\circ}$. Observação da turma em atividade de aula expositiva dialogada por outro profissional (professor, coordenador pedagógico, direção ou outro)

$2^{\circ}$ Observar os itens abaixo. Cada item deverá ser registrado por meio de um símbolo e direcionado por uma seta, para que se possa observar a direção da ação do professor para os alunos e dos alunos para o professor e para os colegas:

(A) Aluno (P) Professor

(i) Exposição, explicação; (ii) Pergunta; (iii) Resposta, (iv) Solicitação de silêncio; (v) Admoestação/Reforço negativo; (vi) Reforço positivo; (vii) Corte; (viii) Agressões verbais; (ix) Silêncio; (x) Comunicação aluno com aluno; (xi) Movimentação no espaço.

$3^{\circ}$ Organização da planta da sala de aula e registro das comunicações verbais, a partir dos símbolos criados.

$4^{\circ}$ Análise das comunicações pelo professor e outro profissional. Confrontar a relação entre a mesma e a posição das carteiras, relações de gênero, aluno-aluno, professor-aluno, aprendizagem dos alunos, idade, vizinhança, aspecto físico e outros.

$5^{\circ}$ Análise com os alunos.

$6^{\circ}$ Levantamento de sugestões para uma comunicação mais democrática.

$7^{\circ}$ Aplicação da nova sugestão em sala.

Fonte: Sugestão organizada a partir da Planta da sala de aula proposta por Estrela (2002). 
É preciso constituir relações de reciprocidade dialógica e cooperativa (FLEURI, 2008; FREINET, 1960), promovendo a transformação da sala de aula em espaço de confiança e aprendizagem (ECCHELI, 2008), uma vez que aprendizagem e ensino caminham juntos, influenciando nos processos afetivos, intelectuais e outros. Desta forma, supera-se a unidirecionalidade da relação de vigilância pautada em relações de hierarquia e superioridade por relações mútuas, de assimetria e diferença (AQUINO, 1998a; FLEURI, 2008).

As mensagens na sala de aula são transmitidas tanto pela fala quanto pelas expressões corporais e visuais, por isso, para o entendimento mútuo ser obtido, se faz necessário a superação do olhar unissensorial para as múltiplas dimensões sensoriais, olhar e ser olhado. Nesse sentido, o falar e o escutar deixam de ocorrer entre um sujeito ativo e um passivo e passam à participação ativa e recíproca, haja vista que esta comunicação, por ser multidimensional e complexa, é dialógica (FLEURI, 2008).

Quadro 10 - Diagnóstico e intervenção na sala de aula.

\section{Sugestão: Construção de Normas de Convivência}

1. 0 professor e/ou coordenador pedagógico deverão analisar o quadro abaixo com os alunos

2. Escrever SIM ou NÃO para as situações que estão ocorrendo na sala de aula (professor, alunos e coordenador)

\begin{tabular}{|l|l|l|l|l|l|}
\hline $\begin{array}{l}\text { Situações vivenciadas } \\
\text { em sala de aula }\end{array}$ & $\begin{array}{l}\text { Aluno e } \\
\text { Aluno }\end{array}$ & $\begin{array}{l}\text { Aluno e } \\
\text { Professor }\end{array}$ & $\begin{array}{l}\text { Situações vivenciadas } \\
\text { em sala de aula }\end{array}$ & $\begin{array}{l}\text { Aluno e } \\
\text { Aluno }\end{array}$ & $\begin{array}{l}\text { Aluno e } \\
\text { Professor }\end{array}$ \\
\hline Diálogo & & Exclusão & & \\
\hline Confiança & & Medo & & \\
\hline Autoestima positiva & & Ameaças & & \\
\hline Autonomia & & Submissão & Ridiculo ou \\
humilhação & & \\
\hline Empatia & & $\begin{array}{l}\text { Silêncio como norma } \\
\text { permanente }\end{array}$ & & \\
\hline $\begin{array}{l}\text { Culto das boas relações } \\
\text { interpessoais }\end{array}$ & & & & & \\
\hline
\end{tabular}

(continuação) 
(continuação)

\begin{tabular}{|l|l|l|l|l|}
\hline \multirow{2}{*}{$\begin{array}{l}\text { Aprendizagem } \\
\text { cooperativa }\end{array}$} & Domínio & & \\
& & $\begin{array}{l}\text { Indiferença no trato } \\
\text { pessoal }\end{array}$ & & \\
& & & \\
\hline $\begin{array}{l}\text { 3. Pactuar normas coletivas de convivência para evitar as situações da quarta coluna } \\
\text { e trabalhar cotidianamente para preservar as da primeira coluna. } \\
\text { 4. Colocar em prática o combinado e retomá-lo sempre que necessário. }\end{array}$ \\
\hline
\end{tabular}

Fonte: adaptado de Jares (2002, p.103).

As condições para que possa emergir a confiança mútua, imprescindivel para uma relação de qualidade entre docente e discente, se constroem por meio de uma comunicação que se paute pelas seguintes características: capacidade de reconhecer, disponibilizar os recursos próprios e incentivar o outro à expressão e disponibilização dos seus recursos; comportamento aberto/próximo; assertivo/direto; empenhado na expressão pessoal, na escuta e compreensão do outro. Assim, os conflitos surgidos são geridos com maior serenidade, por meio de mediação, buscando um acordo pelo diálogo (CARITA; FERNANDES, 2002; CHRISPINO; CHRISPINO, 2011; JARES, 2002). 0 Quadro 10 sugere um diagnóstico e a construção coletiva de normas de convivência. Ressalta-se a importância do respeito por um claro e sempre lembrado código de conduta, para que o desenvolvimento da aprendizagem se efetive (GOMES, 2009).

\section{Concluindo: difícil, mas possivel}

A indisciplina enfrentada na sala de aula não é algo novo e revela diferentes faces ao longo da história da educação, entretanto, não pode ser vista como fenômeno imutável. Retomando as frases de: "Mudar é difícil, mas é possível" (FREIRE, 1997, p. 28) e "A educação sozinha não transforma a sociedade, sem ela tampouco a sociedade muda" (FREIRE, 2000, p. 31), entende-se que é possível reverter o quadro de indisciplina na escola/sala de aula por meio da construção de processos autônomos e solidários, defendidos por Freinet (1996), dialógicos, emancipatórios e cooperativos, como praticados por Freire (1997), numa relação de reciprocidade entre sujeitos educandos/educadores no processo de conhecimento (FLEURI, 2008).

Para refletir sobre as ações do cotidiano da sala de aula, esta seção apresentou alguns procedimentos inadequados que precisam ser evitados, já que podem provocar a indisciplina. Sintetizando-os segundo a literatura apresentada, se tem:

(i) Permissividade (descontrole da aula, ineficácia na aprendizagem).

(ii) Indiferença (rotina, monotonia).

(iii) Autoritarismo (rigidez, agressividade, prepotência). 
(iv) Vigilância pautada em relações de hierarquia e superioridade.

(v) Falta de confiança mútua.

(vi) Normas vagas e procedimentos desajustados, com diretivas pouco precisas.

(vii) Falhas na comunicação.

(viii) Comunicação ambígua das expectativas e/ou distribuída irregularmente.

(ix) Rotulagem do aluno como indisciplinado e mal educado, relacionando esse comportamento ao da família.

(x) "Negociar" abertamente o silêncio por uma atividade considerada prazerosa.

(xi) Elogiar uma turma como a mais comportada, gerando rivalidade entre ela e outras.

(xii) Aulas monótonas ou mal preparadas.

(xiii) Metodologias inadequadas para trabalhar com os alunos que não possuem competências básicas na área da escrita e leitura.

(xiv) Execução do currículo sem considerar o contexto do aluno, os problemas vividos e o diagnóstico de aprendizagem.

As novas exigências requerem do professor competências técnicas e relacionais para trabalhar segundo os princípios de liberdade e responsabilidade (ESTRELA, 2002; FREIRE, 1985; FREINET, 1996). Para tanto, se faz necessário uma educação continuada dos educadores, sobretudo daqueles que atuam na regência de turma, para aprofundar estudos dos porquês e adquirir segurança, a fim de aplicar os meios eficazes para a mediação das situações de indisciplina na sala de aula, que constituem barreiras ao processo de aprendizagem. A educação para a paz deve ser uma busca contínua.

\section{Referências}

AMADO, J. A indisciplina e a formação do professor competente. [S.I., 20-?]. Disponivel em: <www.educ.fc.ul.pt/recentes/mpfip/pdfs/joaoamado.pdf>. Acesso em: 06 out. 2009.

AQUINO, J. G. A indisciplina na escola atual. Revista da Faculdade de Educação, São Paulo, v. 24, n. 2, p.181-204, jul./dez. 1998a.

A violência escolar e a crise da autoridade docente. Cadernos Cedes, Campinas, v. 19, n. 47, p. 7-19, dez. 1998 b.

BARBOSA, M. C. S.; XAVIER, M. L. Os primeiros estudos. In: XAVIER, M. L. (Org.). Disciplina na escola: enfrentamentos e reflexões. Porto Alegre: Editora Mediação, 2006, p. 23-31.

BEANE, A. L. A sala sem bullying. Porto: Porto Editora, 2006.

BOGGINO, N. Cómo prevenir la violencia en la escuela: estudio de casos y orientaciones prácticas. Rosario: Homo Sapiens Ediciones, 2005. 
CAEIRO, J.; DELGADO, P. Indisciplina em contexto escolar. Lisboa: Instituto Piaget, 2005.

CARITA, A.; FERNANDES, G. Indisciplina na sala de aula. Lisboa: Editorial Presença, 2002.

CHRISPINO, A.; CHRISPINO, R. S. P. Políticas educacionais de redução da violência: mediação do conflito escolar. 2. ed. São Paulo: Biruta, 2011.

COLOMBIER, C.; MANGEL, G.; PERDRIAULT, M. A violência na escola. São Paulo: Summus, 1989.

DEBARBIEUX, É.; BLAYA, C. Violência nas escolas e políticas públicas. Brasília: UNESCO, 2002.

DELORS, J. et al. Educação: um tesouro a descobrir. São Paulo: Cortez, 2001.

DEMO, P. Éticas multiculturais: sobre convivência humana possível. Petrópolis: Vozes, 2005.

DEWEY, J.Vida e educação. 5. ed. São Paulo: Editora Nacional, 1959.

DURKHEIM, É. As regras do método sociológico. São Paulo: Ed. Martin Claret, 2002.

ECCHELI, S. D. A motivação como prevenção da indisciplina. Educar em Revista, Curitiba, n. 32, p.199-213, 2008.

ESTRELA, M. T. Relação pedagógica: disciplina e indisciplina na aula. 4 ed. Porto: Porto Editora, 2002.

FELOUZIS, G. A eficácia dos professores. Porto: Rés, 2000.

FLEURI, R. M. Entre disciplina e rebeldia na escola. Brasilia: Liber Livro Editora, 2008.

FOUCAULT, M. Vigiar e punir: história da violência nas prisões. 18. ed. Petrópolis: Vozes, 1998.

FREINET, C. L'education morale et civique. 5e éd. Cannes: Editions de l'Ecole moderne francaise, 1960. p. 86. (Série Bibliotheque de l'ecole moderne.). Disponivel em: <http://www.icem-pedagogie-freinet.org/node/18125>. Acesso em: 07 ago. 2009. . Pedagogia do bom senso. São Paulo: Martins Fontes, 1996. 
FREIRE, P. Pedagogia do oprimido. Rio de Janeiro: Paz e Terra, 1985.

. Pedagogia da autonomia: saberes necessários à prática educativa. São Paulo: Paz e Terra, 1997.

. Pedagogia da indignação: cartas pedagógicas e outros escritos. São Paulo: UNESP, 2000.

GADOTI, M. Projeto político-pedagógico da escola cidadã. In: Salto para o futuro: construindo a escola cidadã: projeto político-pedagógico. Brasilia, DF: Ministério da Educação e do Desporto, Secretaria de Educação a Distância, 1998, p. 15-22.

GOMES, C. A. A educação em novas perspectivas sociológicas. 4. ed. São Paulo: Ed. Pedagógica e Universitária, 2005.

Poder, autoridade e liderança institucional na escola e na sala de aula: perspectivas sociológicas clássicas. Ensaio: aval. pol. públ.edu. Rio de Janeiro, v. 17, n. 63, p. 235-261, abr./jun. 2009.

GOMES, C. A.; PEREIRA, M. M. A formação do professor em face das violências nas escolas. Cadernos de Pesquisa, São Paulo, v. 39, n. 136, p. 201-224, jan./abr. 2009.

GOMES, M.; LOPES, R. B. Percepção dos professores do ensino fundamental sobre indisciplina na escola. In: SEMINÁRIO DE PESOUISA E PÓS-GRADUAÇÃO, 6., 2005, Montes Claros; SEMINÁRIO DE INICIAÇÃO CIENTÍFICA, 4., 2005, Montes Claros. Anais... Montes Claros: Universidade Estadual de Montes ClarosUnimontes, 2005.

G0OD, T. L.; BROPHY, J. E. Looking in classrooms. Nova York: Harper \& Row, 1984.

JARES, X. R. Educação e conflito: guia de educação para a convivência. Porto: Asa Editores, 2002.

KOUNIN, J. S. Discipline and group management in classrooms. New York: Holt, Rinehart and Winston, 1970.

LAPASSADE, G. Grupos: organizações e instituições. 3. ed. Rio de Janeiro: Francisco Alves, 1989. 
LOBROT, M. A favor ou contra a autoridade. Rio de Janeiro: Francisco Alves, 1977.

MACHADO, N. J. Educação: projetos e valores. 3. ed. São Paulo: Escrituras, 2000.

MANACORDA, M. A. História da educação: da antiguidade aos nossos dias. 6. ed. São Paulo: Cortez, 1997.

OLIVEIRA, V. A.; LOPES, R. B. Indisciplina no cotidiano da sala de aula: estudo de caso. Humanidades: revista dos cursos das Ciências Humanas, Montes Claros, v. 1, n. 2, p. 18-28, jan./dez. 2006.

PEREIRA, B. O. Para uma escola sem violência: estudo e prevenção das práticas agressivas entre crianças. 2. ed. Coimbra: Fundação Calouste Gulbenkian; Fundação para a Ciência e Tecnologia, 2008.

PEREIRA, L. A escola numa área metropolitana. São Paulo: Pioneira, 1967.

PERRENOUD, P. Dez novas competências para ensinar. Porto Alegre: Artes Médicas Sul, 2000.

PIAGET, J. O julgamento moral na criança. São Paulo: Mestre Jou, 1977.

RATHS, L. E. Ensinar a aprender: teoria e aplicação. 2. ed. São Paulo: Herder, 1977.

ROGERS, C. R. Liberdade para aprender. 4. ed. Belo Horizonte, MG: Interlivros, 1978.

SAVIANI, D. História das idéias pedagógicas no Brasil. 2. ed. Campinas: Autores Associados, 2008.

TULESKI, S. C. et al. Voltando o olhar para o professor: a psicologia e a pedagogia caminhando juntas. Revista do departamento de psicologia, Niterói, v. 17, n. 1, p. 129-137, jan./jun. 2005.

VEIGA, I. P. A. Projeto político pedagógico da escola: uma construção possível. Campinas: São Paulo, Papirus, 1998.

XAVIER, M. L. Os incluídos na escola: a negação do processo de disciplinamento. In:_ (Org.). Disciplina na escola: enfrentamentos e reflexões. 2. ed. Porto Alegre: Editora Mediação, 2006, p. 145-157. 